ConNotas. Revista de Crítica y teoría literarias / Vol. VI, Núm. 10 / 2008

\title{
Monja y casada, virgen y mártir y Martín Garatuza: dos formas complementarias de argumentación
}

\author{
Marco A. Chavarín ${ }^{*}$
}

Resumen:

Entre 1868 y 1872 los escritores liberales mexicanos intentaron convencer de las bondades de su ideología mediante dos subgéneros, la novela histórica y la novela de folletín. A partir de estas estructuras Vicente Riva Palacio escribió siete novelas. Las dos principales y las que más han llamado la atención, quizá las mejores, son Monja y casada, virgen y mártir y su secuela, Martín Garatura, ambas de 1868. Sobresale en las dos la estrategia folletinesca que implica cumplir con las expectativas de un lector que paga por que así sea, por que se le otorgue el consuelo de la catarsis. Sin embargo, en Monja y casada, virgen y mártir se le niega y en Martín Garatuza se le otorga. Mi propuesta de lectura es que en la primera se argumentan y en la segunda se reafirman los beneficios del liberalismo a partir de la asimilación de los distintos recursos de la novela histórica, pero sobre todo, de la novela de folletín.

Palabras clave:

Vicente Riva Palacio, novela histórica, novela de folletín, novela decimonónica, liberalismo, Ignacio Manuel Altamirano.

En 1867, tras la caída del Segundo Imperio en México, los liberales tratan de conseguir la paz mediante la generación de más adeptos a su ideología, pues "el triunfo en el campo de batalla no era bastante 
[...buscaban] también apoderarse de las conciencias" (Ortiz 93). Una de las razones para semejante búsqueda, como se recordará, fueron las luchas durante casi medio siglo entre liberales y conservadores. Juárez intenta, entonces, hacerse de "esas conciencias" mediante una doctrina menos subversiva que el liberalismo -que en esencia es bastante revolucionario-, el positivismo, que como Zea señala fue importado "para servir [...] a un [...] grupo político" (28), pues sólo así podía justificarse su permanencia en el poder; otros, más apegados a las ideas liberales, lo intentan desde la literatura. Como ejemplo de esto último se tienen las Veladas literarias, esas reuniones - propuestas por Luis G. Ortiz y José Tomás de Cuéllar (Clark 99)- en las que participaron los escritores -liberales y conservadores- más importantes de aquella época. Los principales postulados establecidos en estas tertulias se encuentran en Revistas literarias de México (1821-1867), de Ignacio Manuel Altamirano, y pueden reducirse a dos necesidades, una estética y otra ética: 1) una Literatura Nacional (Altamirano 32) y 2) una literatura con "misión patriótica" (Altamirano 37).

Entre 1868 y 1872 -periodo que es considerado por algunos críticos como el auge de la novela histórica y de folletín (Orozco 9)- aparecieron también algunas novelas que se basaban en las ideas propuestas en las Veladas literarias y que se han considerado más como respuesta al llamado de Altamirano que como una reacción simultánea. Cinco novelas representativas de este fenómeno son: El Cerro de las Campanas (1868), de Juan Antonio Mateos, Calvario y Tabor (1868), de Vicente Riva Palacio, El pecado del siglo (1869), de José Tomás de Cuellar, Clemencia (1869), de Ignacio Manuel Altamirano, y Los mártires del Anábuac (1870), de Eligio Ancona. Todas estas obras literarias fueron construidas con base en dos estructuras, la novela histórica y la novela de folletín francesa, subgénero, sobre todo este último, que fue entendido como el medio ideal para transmitir las ideas a las masas y que dio como resultado el auge mencionado:

En 1869 [...] Ignacio Manuel Altamirano, el primer gran teórico de la literatura mexicana -vale decir, el Padre de la Litera- 
tura Nacional-, reconocía que por el constante estado de guerra vivido en el país durante los 48 años de existencia independiente, se habían desarrollado poco las Bellas Letras en México. Añadía que, de esa parca producción, sobresalía el cultivo de la novela histórica, en demérito de la verdadera poesía, según él, la novela sentimental. (Bobadilla 9)

En el presente artículo se considerarán las novelas Monja y casada, virgen y mártir y Martín Garatuza -ambas de 1868-, de Vicente Riva Palacio (1832-1896), como estructuras discursivas, adscritas a la doctrina liberal, que fueron construidas para convencer de las posibilidades de la visión de mundo que representaban.

En Monja y casada, virgen y mártir, se narra la tragedia de doña Blanca de Mejía y las aventuras de Martín Garatuza. Por un lado, la vida de la primera se ve sometida a la avaricia de su hermanastro don Pedro de Mejía, quien no deseando compartir la mitad de su herencia con ella, antes de que cumpla 20 años o se pueda casar -según las cláusulas testamentarias-, la obliga a contraer el hábito de Santa Teresa la antigua; tras siete años de enclaustramiento huye del convento para casarse con don César de Villaclara -tal como refiere el título: Monja y casada-, es atrapada y torturada por la Inquisición, se escapa nuevamente, es raptada por un bandido y, finalmente, se lanza a un barranco para evitar ser violada - de ahí lo de virgen y mártir-. Por el otro, Garatuza, quien de forma similar al pícaro sirve a distintos personajes, se ve envuelto en algunas peleas y en la mayoría de las intrigas, las cuales se relacionan directa o indirectamente con la suerte de la heroína.

Tanto doña Blanca como Garatuza son tipos representativos de los criollos y de los mestizos, respectivamente. La primera es un personaje sublimado y, por lo mismo, casi estático que sirve como núcleo horizontal para la acción de diversos personajes de la clase alta, en los tiempos-espacios cerrados. El segundo es un personaje picarizado y muy dinámico (Riva, Monja y casada 33), que sirve de vínculo entre la clase alta y la baja del México colonial, en los tiempos-espacios abiertos. Los dos personajes cumplen en conjunto con una función similar a la del personaje principal de la novela históri- 
ca, aquel que Lukács denominó héroe medio y que, posteriormente -si se sigue la propuesta de Ignacio Ferreras de que la novela de folletín es una variación de la novela histórica (Román 130)-, se convierte en el héroe de folletín. El rompimiento, al final de la novela, con las expectativas del lector, resumidas en el final feliz, se da debido a la tendencia a la sublimación de doña Blanca. Su cumplimiento es uno de los rasgos característicos de la estructura folletinesca. Por tanto, el incumplimiento en este contexto resulta la prueba central de lo poco funcional de la visión del mundo conservadora, identificada con el tiempo-espacio de la Colonia. Umberto Eco dice al respecto que hay dos maneras en que puede entenderse el término catarsis de Aristóteles:

En la primera de ellas, la catarsis deshace el nudo de la trama, pero no reconcilia al espectador consigo mismo: antes bien, el desenlace de la historia no viene sino a plantearle nuevos problemas [en la segunda...] la trama, al desenredar los nudos, se consuela y nos consuela. Todo acaba como se quería que acabara. (El superhombre de masas 16-17)

Como el mismo Eco sugiere, la novela de folletín concuerda con el segundo tipo; sin embargo, como se ha señalado, el final de Monja y casada, virgen y mártir corresponde más al primero, lo que supone la manipulación de la estructura con el fin de apoyar la visión del mundo liberal.

Vale reiterar que el principal argumento a favor de la visión del mundo liberal de la novelística de este periodo $-\mathrm{y}$ no sólo de la de Riva Palacio- fue la descalificación de la ideología conservadora, mediante la degradación de un tiempo-espacio directamente relacionado con ella. Por ejemplo: en seis de las siete novelas, que Riva Palacio publica entre 1868 y 1872, el significado de la Colonia se reduce a la leyenda negra de la Inquisición. En El pecado del siglo, de Cuéllar, los problemas educativos se adjudican a la visión del mundo de la Colonia. Asimismo, en Los mártires del Anábuac, de Ancona, la imposibilidad de la realización amorosa se debe a la Conquista, que da inicio al periodo de la Colonia. Algo similar parece suceder 
con el tiempo-espacio situado en la guerra contra el Segundo Imperio, en el caso de El Cerro de las Campanas, de Mateos, Calvario y Tabor, de Riva Palacio, y Clemencia, de Altamirano, donde ninguno de los protagonistas puede realizarse individualmente hasta que varíe el régimen político, del conservador -representado por Maximiliano y la aristocracia mexicana que lo trajo- al liberal, la República Restaurada.

Dos son, por tanto, los argumentos que se presentan en Monja y casada virgen y mártir a favor del liberalismo: la representación física degradada del tiempo-espacio de la Colonia y el efecto de ello, el sometimiento del individuo a fuerzas externas que no puede controlar. Esto último es perceptible en la subordinación de la individualidad de los personajes a la autoridad arbitraria de la Santa Inquisición, donde se trata de generar un estado de terror parecido a la sensación de lo siniestro, término sugerido por Sigmund Freud en su ensayo del mismo nombre. Con base en el análisis del "Hombre de la arena", de Hoffmann, Freud dice que la sensación de lo siniestro puede generarse de dos maneras, por reanimación de recuerdos infantiles reprimidos o "cuando convicciones primitivas superadas parecen hallar una nueva confirmación” (59). Es decir, lo siniestro, en el segundo caso, aparece al ratificarse una creencia que antes había sido desmentida por su enfrentamiento con la realidad. Esta última es la que se utiliza en Monja y casada, virgen y mártir debido a la tendencia de la novela histórica al anacronismo, pues lo siniestro por confirmación permite el uso de un tiempo-espacio del enunciado coincidente con la realidad del tiempo-espacio del emisor y -para el caso de los lectores del XIX- del receptor, proporcionando así un excelente artificio estético y retórico para convencer al lector de la idea planteada:

el poeta puede exaltar y multiplicar lo siniestro mucho más allá de lo que es posible en la vida real, haciendo suceder lo que jamás o raramente acaecería en la realidad [...] nos engaña al prometernos la realidad vulgar, para salirse luego de ella. Reaccionamos ante sus ficciones como lo haríamos frente a nuestras propias vivencias; una vez que nos damos cuen- 
ta de la mistificación, ya es demasiado tarde, pues el poeta ha logrado su objeto. (Freud 61-62)

Es de esta manera que la pérdida de la individualidad ante la arbitrariedad del tiempo-espacio, que en este caso específico genera la sensación de lo siniestro, se relaciona, además, con el espacio fronterizo en el que se convierte la Colonia. Esta equiparación entre espacios es válida si el segundo se entiende como una zona de transición entre algo que ya no se es, español e indígena, y lo que se comienza a ser, "los hijos de español y negra, mulatos; los de español e india, mestizos; los de indio y negra, zambos; luego una porción de subdivisiones, como pardos, coyotes, saltapatrás, etc." (Riva, Monja y casada 86). Todas estas subcategorías, como se sabe, a la larga fueron incluidas en una sola, la de mestizo. La falta de identidad del yo, a manera de sinécdoque de la falta de identidad nacional, entonces, puede entenderse como la falta de individualidad, si se acepta que un individuo sólo puede ser aquel que tiene conciencia de serlo.

La tercera novela de Riva Palacio, secuela de Monja y casada, virgen y mártir, es Martín Garatuza; en ésta se narran las aventuras del héroe homónimo, que se centran, por un lado, en su participación en una conspiración criolla y, por otro, en la venganza tardía por la muerte de doña Blanca y la búsqueda de la felicidad de la sobrina de ésta, doña Esperanza de Carvajal. El desenlace, a la manera de Los tres mosqueteros cuando Milady es juzgada por Athos y ajusticiada en un paraje solitario, consuela al lector cuando son ejecutados don Alonso de Rivera -amigo de don Pedro de Méjía, el hermano de doña Blanca-, don Baltasar de Salmerón -el villano- y Guzmán -quien había provocado el suicidio de doña Blanca- por don César de Villaclara -viudo de doña Blanca-, Martín Garatuza y el negro Teodoro, a las afueras de la ciudad de México, "rumbo a la laguna". Al final, doña Esperanza y don Leonel se casan y son ricos y felices para siempre.

En Martín Garatuza, si bien se retoman algunos hechos históricos y a la Inquisición como sinécdoque del periodo de la Colonia en la Nueva España como en Monja y casada, virgen y mártir, se busca 
más que nada consentir a un lector cautivo, al que se había buscado antes transmitir la idea de la doctrina liberal como esencial para el progreso. En esta novela, por tanto, se reafirman los valores transmitidos en la anterior y se demuestra que sí puede haber lugar para la felicidad individual. Es decir, en Martín Garatura, a diferencia de su novela predecesora, sí se otorga el consuelo final al lector, como una manera de reafirmar las ventajas del liberalismo sobre la visión del mundo conservadora. Es necesario señalar que esto es posible gracias a que Garatuza tiene una mentalidad del siglo XIX -obvio anacronismo- y a pesar de la degradación del tiempo-espacio de la Colonia -característica que también posee esta novela-.

De los dos cronotopos de la aventura, adoptados en general por la novela europea y en particular por la novela histórica de Scott, mencionados por Mijail Bajtín en Teoría y estética de la novela, el de prueba, griego, y el costumbrista, romano, predomina el primero. De ahí que exista una especie de hiato entre el inicio en que se reencuentran doña Esperanza y don Leonel, después de algunos años de no verse, y el final en que se casan. El hiato es como una pausa, "como si la boda [entre los personajes] se hubiera efectuado al segundo día después del encuentro" (Bajtín 242). De acuerdo con Bajtín, la no importancia de lo que ocurre entre en el inicio y el final de la novela radica en que toda la trama de la novela de aventuras griega se reduce a una serie de pruebas, de las cuales el héroe debe salir triunfante evitando el cambio de su situación inicial. Esta hazaña del héroe resulta en una ampliación del rango de lo posible, dentro de lo aceptable como verosímil, permitiendo acciones imposibles para otro tipo de novela donde los personajes evolucionan como consecuencia de sus aventuras, ya que "no hay nada en él [el tiempo-espacio de la aventura griego] que limite el poder absoluto del suceso" (Bajtín 254).

El personaje principal es Martín Garatuza y al igual que en Monja y casada, virgen y mártir aparece picarizado, pero a diferencia de esta última, el personaje no evoluciona, pues su maduración ya se había completado. Sin embargo, de manera distinta a la anterior novela, existe un énfasis en las cualidades positivas de Garatuza que lo acerca al nivel del superhombre, característica inmanente al 
héroe folletinesco. Para Antonio Gramsci, en la novela de folletín se prefiguró el superhombre nietzscheano. Aunque su primer comentario es irónico, "el mismo Nietzsche ¿no habrá estado influido en algo por las novelas de folletín francesas?" (142), no deja de ofrecer datos -igual de irónicos, pero- concretos respecto de la novela de folletín que "se difundió mucho entre los intelectuales, por lo menos hasta 1870" (Gramsci 142).

Umberto Eco, quien retoma la propuesta de Gramsci, dice que en la novela de folletín "El superhombre es el engranaje imprescindible para el buen funcionamiento del mecanismo consolatorio; hace que los desenlaces de los dramas resulten inmediatos e impensables; consuela enseguida y consuela mejor" (56). Irónicamente o no, la idea resulta interesante, pues el superhombre puede verse como un tipo de superhéroe, un ideal buscado por el hombre. En Friedrich Nietzsche, el superhombre -arriesgándome a ser simplista- es la liberación de la conciencia moral, al asumirse como un hecho la muerte de Dios, un estado de independencia psicológica muy difícil de alcanzar, donde el sujeto es capaz de lograr la transmutación de todos sus valores y asumir plenamente sus decisiones, incluso la de la venganza, principal móvil de la novela de folletín.

Hay, sin embargo, una diferencia esencial entre el héroe de folletín y el superhombre de Nietzsche: la transmutación de valores que remiten a la prefiguración del superhombre nietzscheano se justifica en Martín Garatuza mediante la subordinación del actuar del personaje a un poder providencial; por ejemplo, cuando el negro Teodoro menciona "¡Dios le ayude! La venganza es mala pero quizá esta vez sea sólo un acto de la justicia del cielo" (Riva, Martín Garatuza 124). Esta reacción del personaje tiene que ver, más que nada, con el cumplimiento de las expectativas de un lector común, cuyos límites transgresores los pone, por lo regular, el discurso religioso; lo mismo sucede con Dantés, quien

se saca de la manga el as de la Misión Divina [pues...] casi al final de su empresa, se apodera de él la duda, teme haber abusado de su poder, pero al final caen en sus manos los manuscritos secretos del abate Faria y lee el siguiente epígrafe: 
'Arrancarás los dientes del dragón y aplastarás con tus pies a los leones, dice el Señor'. ‘Ah!... ¡Aquí está la respuesta!', exclama Montecristo. Y tan contento está de haberla encontrado que, tras edificar debidamente a lector - no hay superhombre que no sea un subdios-, se permite incluso infringir la regla de perversa castidad que le había sido impuesta por la venganza: podemos verlo navegando feliz por las playas desconocidas al lado de la mujer que lo amaba en silencio, y convertido de nuevo en hombre para no desilusionar a los compradores del folletín. (Eco, El superhombre 97-98)

Uno de los principales motivos desencadenadores de la historia narrada en Martín Garatuza es la discriminación de los criollos -el término incluye a criollos y mestizos- por parte de los peninsulares, los cuales proclaman la superioridad europea y exigen de aquéllos el sometimiento completo a la visión del mundo imperialista española. Este tipo de situaciones, de acuerdo con Rosalba Campra, provoca en la visión del sometido, el conquistado, la costumbre de asumir, a manera de máscara, una identidad ajena, exigida por el poderoso, el conquistador, para permitirle existir en su mundo. En ese universo, la prohibición de la imaginación lleva a "La conducta mimética [que] aparece entonces como única existente; la máscara como el único rostro aceptable" (Campra 18), donde "el constante cambio de identidad de Garatuza apuntala [...] el importante asunto de los criollos, de su desazón ante un árbol genealógico [que...] ayuda a los demás personajes que se debaten intensamente en la reivindicación de su origen" (Algaba 22). Esta "apropiación de los códigos de comportamiento y de comunicación del Otro así como de sus valores llevaría [entonces] a cierta semejanza entre ambas culturas y atenuaría, por lo tanto, la amenaza que emana de la alteridad para la propia identidad" (Seydel 331). Es de suponerse, entonces, que el disfraz adquiera gran importancia en la novela, como en el caso de Garatuza, pues facilita el acceso al mundo del conquistador -del otro- y permite, además, resaltar la importancia de la identidad. La necesidad de aparentar, entonces, es una cons- 
tante en la novela, como sobresale en la llegada del virrey don Rodrigo Pacheco Osorio:

Las calles principales de la ciudad de México se vestían de arcos y de cortinas, los ricos ponían en sus balcones aparadores en donde se ostentaban soberbias vajillas de plata y oro, y toda la población estaba inquieta [...] las campanas de las iglesias repicaban a vuelo, y los cohetes se cruzaban en todas direcciones. Parecía aquello una verdadera ovación popular, y sin embargo un observador cuidadoso podría haber advertido que aquellas manifestaciones tenían más de aparentes que de cordiales [...] pasó la comitiva; la concurrencia comenzó a dispersarse y las calles a quedar más tristes que de costumbre; a la ficticia alegría de la fiesta sucedía el temor del provenir; cada familia temblaba por alguno de sus miembros mezclado más o menos en el negocio del tumulto, y cada familia veía un peligro en la llegada de los nuevos gobernantes. (Riva, Martín Garatura 67-69)

El disfraz, por tanto, es un ardid en la guerra de intrigas -especie de disfraz de las acciones-, que permite manipular la casualidad -particularidad estética cohesionadora de la novela de folletín- al asumir otra apariencia en un tiempo-espacio en el que ésta lo es todo. Este intento de imposición de la voluntad sobre el destino, ya se sabe, tampoco es ajeno a Nietzsche: “Todo 'Fue' es un fragmento, un enigma, un espantoso azar - hasta que la voluntad creadora añada: 'ipero yo lo quise así!'” (211). Debido a la necesidad de manipular la casualidad, ésta y la apariencia están íntimamente ligadas. El disfraz, por tanto, permite a Garatuza, como superhéroe que es, la posibilidad de transgredir tanto lo ético como lo físico; lo ético en cuanto a los valores representados en los demás personajes con atribuciones positivas, incapaces de salirse de la línea aristocrática, y lo físico no sólo en cuanto a la capacidad de movilidad social, a través de los distintos grupos de poder, sino también de defensa ante la fatalidad de las circunstancias, características, todas, que lo hacen parecer incluso un ser con el don de la ubicuidad: 
"Martín era un tipo raro, era una especie de Proteo, siempre en movimiento, siempre variando de forma, y apareciéndose en todas partes y cuando menos se le esperaba" (Riva, Martin Garatuza 236).

Otro elemento que en la novela de folletín se une a la idea del superhombre y el disfraz es el poder económico, pues la posibilidad de establecer todo un sistema ético desde una óptica muy individual sólo se logra a partir del engaño de la casualidad a través de la simulación -intriga- y mediante las grandes ventajas que otorga una buena posición económica. Respecto a este último punto, la necesaria identificación del lector con el personaje principal de la novela de folletín se da en función de una añoranza popular entre la condición de tener para poder, de la cual hacen gala el príncipe Rodolfo de Los misterios de París y Edmundo Dantés de El conde de Montecristo. No es gratuito el comentario irónico de Marx y Engels en La sagrada familia respecto al personaje principal de la novela de Dumas:

El medio prodigioso de que Rudolph se vale para lograr todas sus redenciones y sus curas maravillosas no son sus hermosas palabras, sino que es su dinero contante y sonante. Así son los moralistas, dice Fourier. Tendría uno que ser un millonario, para poder imitar a sus héroes. (Marx 266)

Garatuza no pertenece a la clase alta, sino más bien a la media baja; sin embargo, la presencia del negro Teodoro, solvente económicamente, de don César de Villaclara -noble y rico disfrazado de mendigo- y su capacidad de sangrar a las clases altas para cumplir con sus propósitos, representan el poder económico como complemento infalible de la intriga, pues "Las riquezas en manos del caritativo son como la lluvia sobre los prados secos y áridos" (Riva, Martín Garatuza 398). A pesar de estas coincidencias, la tendencia de Garatuza hacia la picarización lo vuelven un personaje que se vale más de la intriga pura que de la que requiere del apoyo económico. Aunque ello sólo implica la autosuficiencia del mismo.

La "casualidad emprendedora específica del tiempo de la aventura de tipo griego" (Bajtín 249) es uno de los elementos de cohesión 
más importantes en Martín Garatuza, pues su estructuración mediante una serie de encuentros y no encuentros delimitados por las circunstancias -que no se refiere a otra cosa el término de Bajtín-, lleva a lo que Eco llama estructura iterativa, acumulación de acciones, a partir de la cual se puede extender la trama al infinito -cualidad que acaba cuando el lector empieza aburrirse-. Cabe mencionar que el crítico italiano distingue entre dos tipos de estructuras iterativas, una que se podría denominar iterativa consumativa, en la que los hechos afectan a los personajes, y otra iterativa no consumativa, en la que los hechos no los afectan, ambas con el objeto de provocar el consuelo en el lector mediante su encuentro con posibilidades recurrentes en este tipo de novelas. Es decir, el lector, según Eco, haya placer en encontrarse con tramas que ya conoce, por ejemplo, que los protagonistas terminen juntos, después de superar todas las pruebas. Para el caso de las novelas aquí analizadas, ambas poseen una estructura iterativa no consumativa, dependiente del hiato correspondiente al tiempo-espacio de la aventura de tipo griego. Esto es, a diferencia de Monja y casada, virgen y mártir, los personajes de Martín Garatuza dependen de una estructura iterativa no consumativa que se repite hasta el hartazgo. Es decir, los personajes no evolucionan porque sus acciones se circunscriben al área del hiato, donde todo lo que ocurre no afecta a los personajes significativamente.

Eco dice que el Superman de la historieta no envejece debido a la estructura iterativa no consumativa enmarcada en una especie de atmósfera onírica ("El mito" 236), pues la serie de eventos que finalizan en un número del cómic vuelven a empezar en el siguiente, sin tomar en cuenta que el conjunto de acciones anteriores tuvo que haber transcurrido necesariamente en determinado tiempo. Esta paradoja la provocan dos necesidades: que Superman además de ser un héroe mítico, es decir inconsumible, debe sumergirse en la vida cotidiana para ser aceptado, lo cual lo vuelve consumible, es decir mortal. Lo contrario, volverlo inmortal, un dios, rompería la identificación de los lectores con su doble personalidad, Clark Kent (Eco, "El mito" 232). Este último punto pone en evidencia la causa por la cual Riva Palacio vuelve a Garatuza en Martín Garatuza, 
un ser infalible y a la vez con una tendencia hacia la picarización, pues si por un lado lo convierte en la proyección de los ideales no realizados de un lector del siglo XIX, por el otro lo identifica directamente con una ética común a una masa decimonónica, que no podría equipararse totalmente con los ideales caballerescos de los aristócratas del XVII.

Tanto Monja y casada, virgen y mártir como Martín Gatatura, queda visto, son estructuras estéticas con un fin retórico. Las dos descalifican el tiempo-espacio de la Colonia y, en consecuencia, el proyecto conservador que veía más beneficios en las estructuras feudales y en los privilegios heredados, que en las formas liberales, basadas en la idea del "dejar hacer". Lo siniestro funciona, en la primera novela, como un recurso retórico que subraya las limitantes a las garantías individuales impuestas por un tiempo-espacio arbitrario que imposibilita la realización personal. En Martín Garatuza, sobresale la configuración del personaje principal como héroe de folletín, el cual, como prefiguración del superhombre nietzscheano -obvio anacronismo-, es capaz de desconstruir, y por tanto transgredir, los valores característicos del tiempo-espacio del enunciado para subordinarlo a la ejecución de su voluntad.

Lo más sobresaliente, sin embargo, de la idea que supone la estrecha relación entre las masas y las estructuras novelescas utilizadas por Riva Palacio radica en que las ventajas del folletín sólo pudieron ser asumidas plenamente cuando se logró hacer sentir a las personas comunes -los posibles lectores- su directa relación con los hechos históricos. En este último principio se basaron los escritores de novelas históricas y de folletín para configurar a su héroe. Cabe señalar al respecto que si la circunstancia histórica hubiera negado al pueblo la aventura -posibilidad otorgada por la Revolución francesa al llevar la guerra a las ciudades- hubiera sido imposible aceptar, al grado de identificarse con él, la figura del héroe medio, un personaje sacado del pueblo y aventurero como pocos.

El carácter argumentativo de las dos novelas analizadas radica, entonces, en la equiparación de verdad y posibilidad, pues "solamente lo posible es creíble” (Aristóteles 9, 1551b); es decir, el carácter argumentativo radica en argüir a favor de que las posibili- 
dades son más de las que se observan a primera vista según la lógica o los datos históricos. Sólo así pueden justificarse las inconsistencias históricas de las novelas de Riva Palacio que tanto le fueron criticadas por los conservadores. La casualidad puede comprenderse, entonces, como otro tipo de causa, siempre y cuando sea posible. Este conjunto de posibilidades creadas por ambas novelas dependen siempre del grado de verosimilitud -coherencia interna basado en la casualidad emprendedora-, lo que deja de lado la configuración causa-efecto e, incluso, la verdad confirmada. Es ésta una de las formas en que la negación del consuelo en Monja y casada, virgen y mártir y su asunción en Martín Garatuza funcionan como una advertencia de los peligros del viejo régimen, el de la Colonia, convirtiéndose en dos formas complementarias de argumentación.

\section{Bibliografía}

Algaba, Leticia. "Martín Garatuza: Novela e historia." Martín Garatuza. Memorias de la Inquisición. Vicente Riva Palacio. $3^{\text {a }}$ ed. México: Consejo Nacional para la Cultura y las Artes/Universidad Nacional Autónoma de México/Instituto Mexiquense de Cultura/Instituto de Investigaciones Dr. José María Luis Mora, 1997. 11-24.

Altamirano, Ignacio Manuel. "Revistas literarias de México (18211867)." Obras completas. XII. Escritos de literatura y Arte 1. Sel. y pról. José Luis Martínez. México: Secretaría de Educación Pública, 1988. 29-174.

Aristóteles. Poética. Introducción, versión y notas de Juan David García Bacca. $2^{a}$ ed. México: Universidad Nacional Autónoma de México, 2000.

Bobadilla Encinas, Gerardo. Historia y Literatura en el Siglo XIX. La

Novela Histórica Mexicana como un Testimonio Mitico. Hermosillo: Instituto Sonorense de Cultura, 2001.

Bajtín, Mijaíl. "Las formas del tiempo y del cronotopo en la novela." Teoría y estética de la novela. Trabajos de investigación. Tr. Helena 
S. Kriúkorva y Vicente Cazcarra. México: Taurus, 1989. 237409.

Campra, Rosalba. "Razones de la máscara." América Latina: La identidad y la máscara. 2a. ed. México: Siglo XXI, 1998. 13-26.

Clark de Lara, Belem. "El otro José Tomás de Cuéllar." Del Fistol a la Linterna. Homenaje a José Tomás de Cuéllar y Manuel Payno en el centenario de su muerte, 1994. Margo Glantz (coord.). México: Universidad Nacional Autónoma de México, 1997. 99-106.

Eco, Umberto. "El mito de Superman." Apocalípticos e integrados. Tr. Andrés Boglar. México: Lumen-Tusquets, 2006. 219-256.

- El superhombre de masas. Retórica e ideología en la novela popular. Tr. Teófilo Lozoya. $2^{\text {a }}$ ed. Barcelona: Lumen, 1998.

Freud, Sigmund, y E. T. Hoffmann. Lo siniestro. El hombre de arena. Tr. I. Béccar. México: Letracierta, 1978.

Gramsci, Antonio. Literatura y vida nacional. Tr. José. M. Aricó. Buenos Aires: Lautaro, 1961.

Lukács, Georg. La novela histórica. Tr. Jasmin Reuter. México: Era, 1966.

Marx, Carlos, y Federico Engels. La sagrada familia y otros escritos filosóficos de la primera época. Tr. Wenceslao Roces. $2^{\mathrm{a}}$ ed. México: Grijalbo, 1967.

Nietzsche, Friedrich. Asi habló Zaratustra. Intr., tr. y notas Andrés Sánchez Pacual. Madrid: Alianza, 2004.

Orozco Campos, Francisco. "Prólogo." Monja y casada, virgen y mártir. Vicente Riva Palacio. México: Editores Mexicanos Unidos, 1997. 5-15.

Ortiz Monasterio, José. México eternamente. Vicente Riva Palacio ante la escritura de la historia. México: Instituto Mora/Fondo de Cultura Económica, 2004.

Riva Palacio, Vicente. Martín Garatuza. Memorias de la Inquisición. Coord. José Ortiz Monasterio. $3^{a}$ ed. México: Consejo Nacional para la Cultura y las Artes/Universidad Nacional Autónoma de México/Instituto Mexiquense de Cultura/Instituto de Investigaciones Dr. José María Luis Mora, 1997.

Monja y casada, virgen y mártir. México: Océano, 1986. 
Román Gutiérrez, Isabel. Persona y forma: una historia interna de la novela española del siglo XIX. Hacia el realismo. T. I. Sevilla: Alfar, 1998.

Seydel, Ute. Narrar historia(s): la ficcionalización de temas históricos por las escritoras mexicanas Elena Garro, Rosa Beltrán y Carmen Boullosa. Tesis doctoral. Universidad de Potsdam, 2004.

Zea, Leopoldo. El positivismo en México: nacimiento, apogeo y decadencia. México: Fondo de Cultura Económica, 1981. 